\title{
EL MILAGRO ESPAÑOL \\ O EL MITO DEL FRACASO *
}

GASPAR FELIU

Universidad de Barcelona

«El mito del fracaso», extraña transformación del «milagro español» del titulo original inglés, es un libro importante; importante por su ambición: dos siglos de historia de España, con abundantes referencias al antes $y$ al después, importante por la novedad de su tratamiento desagregado y por la atención prestada a la interrelación de los fenómenos económicos políticos y sociales. Pero importante sobre todo porque se trata de una obra de tesis o, por mejor decir, de antitesis. La obra parte de una proposición claramente enunciada: la economía y la sociedad españolas crecieron a largo plazo de una manera continuada desde el siglo xviII o incluso desde finales del siglo xvII, de manera que el «milagro español» de los años setenta no fue más que el resultado y la expresión final de esta larga etapa de crecimiento (pp. 91-92). Este enunciado contradice la tesis dominante sobre la evolución de la economia y la sociedad españolas, la tesis del fracaso de España a la hora de la modernización politica y económica, en su doble vertiente: el fracaso de la revolución burguesa y el fracaso de la revolución industrial.

Con un análisis pormenorizado y apoyado en una imponente bibliografia (41 páginas), que abarca la política y la economía espanolas, pero también la antropologia, la sociologia y la ciencia política, Ringrose pone de relieve los puntos débiles del «mito del fracaso» y aporta datos en defensa de su tesis al. ternativa. Todo ello con una interesante novedad metodológica: el instrumen.

* Nota sobre David Ringrose, Espania 1700-1900. El miso del fracaso Madrid, Alianza Edito. rial, 1996. 
tal urilizado para medir el crecimiento no se saca de la caja de las cifras macroeconomicas estatales (por otra parte tan virtuales en todas partes y con mayor medida en Espana durante gran parte del periodo estudiado), sino del estudio de las redes y las jerarquias urbanas y sociales, que le permite observar "desde dentro" el crecimiento económico y la formación de las elites dominantes del Estado.

La obra se inicia con un prólogo corto y sincero, con dos afirmaciones importantes para la comprensión de la obra: su origen en el contraste entre el pesimismo de la historiografia española y el desarrollismo con que el autor se encontró en su primera visita a España; y su gestación múltiple, a partir de su trabajo inicial sobre el Madrid del Antiguo Régimen, el estudio de otras redes urbanas y una sintesis sobre la economía española del siglo XIX.

Estas diferentes focalidades enriquecen la obra, pero son también responsables de las desigualdades y la falta de trabazón que se observan a veces en ella. Lo mismo puede decirse de su argumentación, enriquecedora, pero de dificil ilación lógica, cuyos pilares son la continuidad del siglo XVIII al XIX (argumentada con el escaso impacto de la pérdida del imperio), la inadecuación del mito del fracaso (puesto que hubo crecimiento continuado) y la improcedencia de denominar «milagrom lo que no es, en opinión de Ringrose, más que una eclosión en la continuidad del crecimiento.

La obra se estructura en cuatro partes, dedicadas, respectivamente: (I) al posicionamiento historiográfico y metodológico; (II) a una visión general de los cambios generados por el comercio y su readaptación tras la pérdida del imperio y al cambio provocado por la redefinición de los derechos de propiedad sobre la tierra; (III) a la caracterización y evolución de las cuatro grandes redes urbanas (Mediterráneo, Cantábrico, Andalucía Occidental y Meseta), y (IV) a la formación de las elites de poder a nivel local y a nivel estatal y a la interrela. ción entre ambas para formar el entramado político del Estado.

La primera parte se abre con la discusión del «problema de la percepción»: ¿por qué la historia de España ha sido vista como un fracaso desde los puntos de vista económico y político? A pesar de las acertadas criticas de Ringrose a la inoportunidad de las comparaciones mediante agregados macroeco. nómicos y a la utilización de Inglaterra como término de comparación, la pregunta «qqué funcionó mal?» no puede ser sustituida con ventaja, como Ringrose pretende, por "¿cómo encajó España en el abigarrado rompecabezas de aceleración del crecimiento económico europeo?» (pp. 53.54), puesto que la misión del historiador es explicar, además de describir; ni tampoco es suficien. te responder con la tautología de que «España funcionó a su ritmo», para admitir a continuación que éste fue comparativamente lento, puesto que a esta 
lentitud, a este ir perdiendo terreno, es a lo que se refieren quienes hablan de fracaso.

Tras la critica a la visión tradicional, Ringrose dedica un capitulo a fijar los conceptos utilizados, con especial hincapié en la importancia y caracteristicas del concepto de innovación (no reducible al cambio tecnológico), una primera caracterización de los sistemas urbanos españoles y de las redes sociales, y de cómo éstas una tras otra transgreden las redes urbanas para ir formando el meollo del Estado, y una advertencia sobre el uso de los conceptos de continuidad y contingencia.

Esta primera parte acaba con un enunciado largo de la tesis propuesta: no hay crecimiento del XVIIl y fracaso del XIX, sino una gran continuidad. La crisis del Antiguo Régimen no fue ni tan severa ni tan diferente a la experimentada por otros paises, ya que quedó circunscrita prácticamente a los ingresos de la monarquía y al estamento comercial gaditano. En cambio, dentro del impulso general de crecimiento europeo, la economía española rompió los frenos mal. thusianos al crecimiento, como se puede observar mediante la evolución favorable de tres indicadores básicos: la población, la renta per cápita y el comercio exterior.

La parte II, «La España peninsular y un mundo en proceso de cambio», dedica sus dos primeros capítulos a reexaminar el comercio americano y su impacto sobre la economia española a lo largo del siglo XVIII, destacando cómo muchos de los cambios legales no son más que tardios reconocimientos de actividades ya bien establecidas y, en especial, cómo Cádiz fue perdiendo importancia real ante la participación creciente en el comercio tanto de los puertos mediterráneos (especialmente Barcelona y su satélite Málaga) como de los puertos cantábricos, dominados en gran parte por capital e iniciativas vascas (comercio directo de San Sebastian a través de la Compañia de Caracas, comercio indirecto de Bilbao a través de Santander y La Coruña). A continuación Ringrose enfatiza la continuidad comercial entre el siglo XVIII y el XIX, haciendo observar, tras discutir las tesis de Fontana y de Prados de la Escosura, que la pérdida del comercio colonial no significó una disminución de la renta nacional superior al $2,5 \%$; resalta también que España se integró bien en el comercio europeo, aunque «se rezagó un poco» $(0,66 \%$ de tasa anual de crecimiento contra $1 \%$ para el conjunto de Europa), que participó en él con gran variedad de productos y que el crecimiento del comercio fue superior al de la población y la renta. Creo que la opinión de Ringrose es en estos aspectos excesivamente optimista, que una pérdida del $2,5 \%$ de la renta nacional, que significa un impacto mucho mayor sobre determinados grupos que hay que suponer como los más activos, representa un fuerte lastre económico y que la 
diferencia de 1 a 0,66 como tasa de crecimiento es algo más que un ligero retraso.

En opinión de Ringrose, las dificultades para el crecimiento económico español dependen de un «cambio de reglas a mitad del juego» (p. 218) impuesto por circunstancias externas a la economia española; aunque no lo dice expre. samente parece querer indicar con ello que "fracaso" deberia reemplazarse por «ineluctabilidad». Este cambio de reglas desfavorable incluye la imposibilidad, por barreras geograficas y edafológicas, de adoptar gran parte de la nueva tecnología agraria; los beneficios coyunturales de la especialización en la exportación de productos primarios; y la mayor dificultad técnica y económica de los nuevos cambios de la segunda revolución industrial. Todo ello en un proceso paralelo a la ruina de las economias interiores basadas en la conjunción artesanado-cerealicultura o ganaderia extensivas, que no pudieron resistir primeramente el impacto de la difusión de la tecnologia textil y más tarde la competencia del cereal transatlántico; en estas condiciones la mejora del transporte no fue un factor de crecimiento, sino de retraimiento, que se intentó paliar mediante el proteccionismo. Añade honradamente que los procesos de crecimiento $e$ innovación (o sus contrarios) pueden verse como efecto del mercado o como resultado de actos politicos y que ambos enfoques son necesarios para la recta comprensión histórica, pero que el libro se basa en la aproximación económica, lo que en la práctica representa dejar de lado las responsabilidades de los gestores de la política económica.

Para cerrar esta segunda parte Ringrose coloca una magnifica exposición sobre el cambio ideológico en la concepción del acceso a la tierra, de su consideración «feudal» como un derecho de los grupos privilegiados, aunque limita. do por fuertes restricciones sociales y políticas, a la consideración capitalista de bien poseible en plena propiedad, sometido a las fuerzas del mercado y libremente alienable; $y$ muestra cómo el paso de una concepción a otra no fue repentino ni revolucionario, ni mucho menos fruto de una imposición desde arriba en el momento de la desamortización, sino de un largo proceso, iniciado como minimo en el último tercio del siglo xvin.

En cambio soslaya el estudio de la transformación de la idea de reforma agraria de una finalidad social a una finalidad fiscal y sobre todo las presiones, no procedentes del mercado, que desviaron la desamortización de una finalidad productora (constitución de una clase de campesinos propietarios, capaces de consumir, ahorrar e invertir) a una finalidad rentista, lo cual tiene que ver sobre todo con la forma en que se llevaron a cabo las licitaciones y con la corrupción que acompañó todo el proceso. Puesto que éste es uno de los pilares básicos de la tesis del fracaso, creo que deberia habérsele dedicado alguna atención. 
Como Ringrose reconoce, «buena parte de lo que se ha proclamado como nuevo y revolucionario en la España de mediados del siglo XIX no era ni una cosa ni otra» (p. 255): el resultado de los procesos de atribución de la propiedad de la tierra y de especialización en la exportación de productos primarios fue el reforzamiento de las elites locales y el acceso de los más fuertes de entre sus miembros a los resortes de poder del Estado, con las secuelas de clientelis. mo y caciquismo inherentes. De hecho este último capítulo resulta mal situado en el conjunto de la obra, puesto que la asignación de la propiedad de la tierra es un factor esencial en las dificultades de adaptación a las nuevas reglas del juego y no algo desligado de las desventuras comerciales o industriales.

La parte III, «Respuestas alternativas a un mundo cambiante», vuelve hacia atrás en el tiempo para explicar la formación y evolución de las redes urbanas y de los cuatro grandes espacios que éstas conforman dentro del territorio estatal. El sistema urbano mediterráneo pone de relieve a la vez la centralidad de Barcelona, la complementariedad de las zonas centradas por el resto de ciudades y las relaciones en el ámbito mediterráneo, especialmente con Marsella y Génova. Señala también correctamente que el comercio colonial fue más consecuencia que causa de la vitalidad económica, y que nunca llegó a significar más del $20 \%$ del comercio barcelonés, mientras que eran de origen espanol más de dos terceras partes del trigo circulante en la zona. Por tanto sólo Málaga se vio fuertemente afectada por la pérdida del comercio colonial, lo que conllevó su separación de la red urbana dirigida por Barcelona para integrarse en la centrada en Sevilla. En conjunto la zona sufrió importantes cambios, pero mantuvo su vitalidad económica y las relaciones comerciales con Europa.

La «España del Cantábrico» es la menos convincente de las redes urbanas definidas por Ringrose. Sólo temporalmente, durante la segunda mitad del siglo xvill, el comercio colonial le da cierta unidad, pero ni la precedencia de Bilbao es suficientemente clara ni los intercambios regionales fueron importantes. En realidad los valles y las estrechas llanuras costeras del Cantábrico tenian economias más semejantes que complementarias y en busca de esta complementariedad la región sufrio siempre importantes tendencias centrifugas. $\mathrm{El}$ mismo Ringrose avala esta inseguridad de la región como espacio económico en sus mapas: hacia 1750 limita la red urbana al espacio entre Cantabria, $\mathrm{Na}$ varra y la Rioja; en 1795 la amplia hasta Galicia y en 1890 incluye en ella casi toda la meseta norte. De hecho Galicia se integra sólo episódicamente en el conjunto y las solidaridades transcantábricas (Santander-Valladolid, BilbaoBurgos-Madrid) son más importantes en el siglo XIX que las relaciones entre los puertos cantábricos. Por otra parte los procesos de industrialización fueron 
no sólo prácticamente independientes, sino a menudo competidores y, fuera del muy tardio desarrollo de la siderurgia vasca, secundarios.

La tercera red urbana es la centrada por Madrid, formada sobre todo por las necesidades de abastecimiento de la corte y en gran parte impuesta politicamente, tema que es bien conocido por los trabajos anteriores de Ringrose. Los privilegios de Madrid crean una serie de relaciones directas de la capital con cada una de las ciudades, limitando mucho las relaciones entre éstas, que por otra parte entran en un proceso de decadencia. Desde el último tercio del siglo xvil la tendencia a la desregularización de los avituallamientos permite a la vez un importante crecimiento del número de habitantes de Madrid y una restricción del área de abastecimiento, posible por los precios remuneradores que ofrecia el mercado madrileño, la puesta en cultivo de tierras antes reservadas a pastos y más tarde el proteccionismo agrario. Con todo ello se produjo un fuerte crecimiento de la España interior, pero un crecimiento tradicional, con escasas oportunidades para la industrialización y en definitiva sujeto a la larga a las restricciones malthusianas; por ello en la frase de Ringrose «es fácil señalar que la agricultura castellana contuvo el surgimiento de España como una sociedad industrial, pero resulta igualmente posible sugerir que [...] posibilitó la considerable modernización del siglo XX» (p. 388), es tan difícil no suscribir la primera parte como estar de acuerdo con la segunda. De hecho la consideración de la evolución de la economia castellana es el nudo central del libro: el crecimiento de la economía de la España interior, la asignación de recursos que la produjo, ¿se acercó al óptimo posible dadas las limitaciones ecológicas y demográficas o bien hubo «razones» políticas que imposibilitaron al. ternativas más eficaces al crecimiento? En el primer caso, el fracaso no sería tal, sino fatalidad; en el segundo, el fracaso sería una desgraciada realidad, con responsables concretos.

La Andalucia de la cuenca del Guadalquivir forma el último de los sistemas urbanos propuestos por Ringrose, quien advierte que no se trata de una articulación tan económica como la mediterránea ni tan política como la de la meseta, pero que participa parcialmente de ambos aspectos y se ve reforzada por una clara unidad geográfica y en una no menor semejanza social, basada en la gran desigualdad a causa de la creciente concentración de la propiedad de la tierra. Aunque la zona muestra un crecimiento importante a lo largo de la época estudiada, Ringrose no puede menos que reconocer que funciona la "trampa de la dependencia»: falta de mercado, escaso estimulo para la producción industrial, dependencia de mercados y capitales extranjeros. Sin que los dos ejemplos que cita sensu contrario sirvan más que para corroborar la dependencia: los vinos de Jerez acabaron en manos inglesas y la casa Carbonell pro- 
cedía de iniciativas ajenas a la región, lo mismo que la siderurgia malagueña o la inversión minera. No se puede negar que exista una lógica capitalista del crecimiento andaluz, que provoca una creciente acumulación de riqueza y poder en manos de la elite, pero no desarrollo, y que, en términos comparativos, hace lícito hablar de subdesarrollo.

En definitiva, el resultado de las diferentes evoluciones de las redes urbanas es un notable crecimiento, pero no comparable con la media de la Europa occidental y, como Ringrose se ve obligado a admitir, la España de 1900, tanto política como económicamente, «contenia mucho que era moderno, aunque también retenia mucho que era vestigio de regimenes anteriores» (pp. 414.415): esta no cumplimentación del proceso de modernización, con el consiguiente retraso respecto a Europa, puede ser considerada claramente como un fracaso.

La parte IV del libro, destinada al estudio de las redes políticas, tanto a nivel local como a nivel estatal, constituye una magnifica revisión de los mecanismos de poder en España y, a la vez y contra los designios de Ringrose, una descripción perfecta de los mecanismos del atraso: si pensamos como ideal en la modernización, con sus secuelas de abolicion de privilegios y de igualdad de oportunidades, estas páginas son un claro alegato en favor de que el fracaso no fue un mito, sino una triste realidad. $Y$ deberian servir también como motivo de reflexión para quienes creen en la validez universal de la smithiana mano invisible, sin pararse a pensar que a menudo la mano visible de los poderosos puede desviarla del bien común al bien particular.

La tesis de Ringrose en este apartado es que las transformaciones posteriores a 1960 no fueron repentinas, sino que tanto la cultura politica de la elite parlamentaria como la cultura económica del capitalismo empresarial estaban presentes de tiempo en la sociedad española; lo que es cierto, pero no lo es la asunción implícita de que eran dominantes. De hecho el texto al describir con gran fineza la interacción entre las elites locales y el gobierno central, los compromisos necesarios para que éste pudiese recaudar impuestos y obtener una apariencia de legitimidad mediante las urnas y el papel del cacique en estas transacciones, no hace más que resaltar la incapacidad de los grupos modernizadores para imponer sus ideas ante la confluencia conservadora (de Antiguo Régimen) de la oligarquía dominante, el ejército y el trono.

El fracaso de la «revolución burguesa» es claramente reconocido por Ringrose cuando afirma que las reformas liberales de la propiedad de la tierra no hicieron más que reforzar la vieja oligarquia y que prácticamente en todo el siglo xix no funcionó el parlamentarismo en España; o cuando, todavía con mayor claridad, afirma que no hubo en Espana revolución burguesa puesto que no hubo una nueva clase media surgida del capitalismo: no hubo más que una 
adaptación de las nuevas formas políticas a las tendencias intelectuales y económicas del siglo anterior (p. 518). El único cambio significativo se dio pues en la forma de transmisión del poder entre los subgrupos oligárquicos: del espadazo al pucherazo.

En definitiva, Ringrose concluye que el comportamiento de los detentores del poder a todos los niveles fue racional en defensa de sus intereses (cosa que nadie duda) y que en 1900 Espana estaba más cerca de la situación actual de lo que los historiadores hemos venido habitualmente diciendo, afirmacion posiblemente cierta, pero todo ello no da cuenta del atraso acumulado respecto a los países del entorno, por lo que no creo que se la pueda considerar como «la genuina y dinámica precursora de la Espana de 1970» (p. 523).

Cuando un alumno suspende, fracasa, no significa que no haya aprendido nada; significa que no demuestra haber aprendido lo suficiente. España antes de la I Guerra Mundial no habia crecido lo suficiente en dos sentidos: no pudo mantener su rango dentro del conjunto de los estados europeos y no aprovechó su potencial de crecimiento y de modernización. La desamortización no significó un mejor cultivo, un incremento del rendimiento de la tierra y un mejor reparto de la renta, con capacidad de estímulo para el mercado y consiguientemente para la inversión, sino la permanencia de unas clases rentistas económicamente ociosas (antes eclesiásticas, después burguesas). La construcción de la red ferroviaria no integró el mercado interior porque la prepotencia de las compañias atendió más al beneficio de la construcción que a la utilidad de la explotación y también porque dejó de lado la posibilidad de apoyar el surgimiento de una industria siderúrgica propia. La modernización política se vio frustrada por la continua falsificación del régimen parlamentario: espado. nes y caciques sostenidos por espadones no son más que las dos caras de la misma moneda. Podemos hablar de fracaso u obviar el término; podemos suspender a un alumno o, utilizando el lenguaje de la pedagogia moderna, decir que «progresa según sus posibilidades», aunque tenga diez años y no sepa leer.

Otro tema. Ringrose estudia la etapa que va de finales del siglo xvil a 1910 para explicar el «milagro» español de los sesenta. Pero la lógica requeriria en este caso no prescindir de una etapa tan fundamental y tan llena de oportunidades y acontecimientos de todo tipo como son los años 1910.1960; lo contrario es ir contra su sensata advertencia de que el camino histórico no está predeterminado, sino que cualquier acontecimiento puede desviarlo completamente. En la práctica el hacer de Ringrose parece argumentar que todo estaba enca- 
rrilado en 1910, que sólo acontecimientos inoportunos (entre ellos el más descarado, violento y desesperado intento de mantener el poder en manos de los de siempre) habian retrasado la eclosión del crecimiento español, olvidando el decisivo impacto exterior en la causación del desarrollo de los sesenta: desde la demanda de complementos alimentarios a la aportación del turismo, las remesas de los emigrantes y la inversión de capital extranjero.

Contra la tesis del crecimiento endógeno y continuista de Ringrose y sin obviar desde luego la importancia y la necesidad de éste como proceso básico, puede levantarse, a mi parecer con un peso superior, la tesis de que el «milagro» español es un sarpullido benéfico provocado por el «milagro» europeo de la segunda postguerra, absolutamente dependiente de éste e inerme ante las crisis que le afectan y que repercuten multiplicadas sobre nuestra economía. A pesar de los cambios, a pesar del indudable crecimiento, continuamos pagando el fracaso de la revolución burguesa y de la revolución industrial.

Estas consideraciones no obstan para que considere que Ringrose ha escrito un gran libro, un libro de obligada lectura; se podrá estar más o menos de acuerdo con su tesis central y con otros puntos de la argumentación, pero la cantidad de información y de discusión cientifica que contiene y la novedad y el acierto de muchos de sus planteamientos sólo son obtenibles con una poco usual capacidad de sintesis y una larga reflexión. Particularmente destacaría como logros la demostración de la continuidad básica entre las economias de los siglos XVIII y XIX, la critica a los aspectos más pesimistas de la teoría del fra. caso (creo que nadie podrá volver a hablar de decrecimiento de la economía española, incluso en términos per cápita), el planteamiento regionalizado, con el seguimiento de tantas interrelaciones y a veces obstáculos al crecimiento, y la atención prestada a las elites locales y a cómo todo el entramado político se restablece a partir de ellas cuando la monarquia de derecho divino ya no resulta una argamasa de consenso suficiente.

Finalmente, el libro de Ringrose tiene el mérito de haber empujado el péndulo de la historiografia española; que, como suele suceder, la oscilación producida haya sido (a mi entender) excesiva no quita el mérito de la presentación de nuevos planteamientos; sólo obliga a intensificar los estudios. De lo que conozcamos mejor en el futuro, una parte del mérito será sin duda del li. bro de Ringrose. 